\title{
A Critical Review of Smart Manufacturing \& Industry 4.0 Maturity Models: Applicability in the O\&G Upstream Industry
}

\author{
Chinedu Onyeme ${ }^{\mathrm{a}, 1}$ and Kapila Liyanage ${ }^{\mathrm{b}}$ \\ College of Science of Engineering, University of Derby, United Kingdom \\ a c.onyeme@derby.ac.uk ${ }^{\mathrm{b}}$ k.liyanage@derby.ac.uk
}

\begin{abstract}
The shift towards Industry 4.0 is a fundamental driver of improved changes observed in today's business organizations. The difficulties in adapting to this new approach pose challenges for many companies especially in the oil and gas $(\mathrm{O} \& \mathrm{G})$ upstream sector. To make this path much feasible for companies in this industry, Maturity Models (MMs) are very useful tools in achieving this following their use in evaluation of the initial state of a company for planned development journey towards Industry 4.0 (I4.0) readiness and implementation. Study shows that only a limited number of $\mathrm{O} \& \mathrm{G}$ specific roadmaps, MMs, frameworks and readiness assessments are available today. This paper aims to review the currently available Industry 4.0 MMs for manufacturing industries and analyze their applicability in the O\&G upstream sector using the systematic literature review (SLR) methodology, recognizing the specific requirements of this industry. The study looks at the key characteristic for $\mathrm{O} \& \mathrm{G}$ sector in relation to the manufacturing sector and identifies research gaps needed to be addressed to successfully support the O\&G sector in readiness for Industry 4.0 implementation. An Industry 4.0 maturity model that reflects the industrial realities for the O\&G upstream sector more accurately from insights drawn from the reviews of existing MMs is proposed. This reduces the challenges of the transition process towards Industry 4.0 and provides support for the critical change desired for improved efficiency in the sector.
\end{abstract}

Keywords. Industry 4.0, Industry 4.0 Maturity Models, Oil \& Gas Industry

\section{Introduction}

Petroleum has been useful to human for so many years and the usefulness is as old as history thus making the $\mathrm{O} \& \mathrm{G}$ industry continuously a competitive market. As a key source of energy over the years, the impact on the Fourth Industrial Revolution would be deemed significant like the manufacturing industry which has remained a major backbone to Industry 4.0. Studies show that the oil \& gas upstream industry and the manufacturing sectors do have much in common as organizations making available products for use by the populace even if they face challenges and barriers different and unique to the industry which are not within the scope of this study. Studies have also shown a much slower pace in adoption of the technologies and components of Industry 4.0 in the $\mathrm{O \& G}$ sectors which are linked to some notable barriers. Findings from this systemic literature review shows that only a few studies specifically focus on supporting the O\&G industry's path towards Industry 4.0 implementation. 'O\&G 4.0 era: A

${ }^{1}$ Chinedu V. Onyeme, College of Engineering and Technology, University of Derby, Markeaton Street, DE22 3AW Derby, United Kingdom; E-mail: c.onyeme@derby.ac.uk.. 
systemic review and outlook' [1]; ' Big data in O\&G industry: An emerging trend'[2]; 'Blockchain Technology in the O\&G Industry: A Review of Applications, Opportunities, Challenges, and Risks'[3]; 'A Vision of IoT: Applications, Challenges, and Opportunities With China Perspective' [4] are some notable areas where authors have studied the subject with some case studies on applicability and transition for the O\&G industry.

\subsection{Industry 4.0 in the $O \& G$ industry \& Maturity or Readiness Model}

In the current world where there is an increasing demand for high performance, customization and high-quality products, the introduction of computers and interaction as machines and computers has become a new order industry and popularly referred to as Industry 4.0. The "Forth Industrial Revolution" is another term for Industry 4.0, it is a further progressive stage in the management and organization of the total value chain process and a link of digital technology solutions for the development of automation, integration and real-time data exchange from the advancement of scientific and production practices in the manufacturing industry [5], [6]. Specialized industry-specific solutions and individualized understanding of customers' needs, increased competitiveness and flexibility from dynamic business processes, optimized decision making due to end-to-end visibility in real time, increasing resource productivity, good work-life-balance, high-wage economy and reduced personal costs are some potentials benefits from Industry 4.0.

Although studies show that more research have been more in application of industry 4.0 in manufacturing but in recent times there have been explorations on the applicability of the core industry 4.0 technologies in the O\&G. One of the key recommendations in the journey is increased focus on personnel development to fully capture the application and benefits from application of the concept of industry 4.0 on the O\&G operations [1]

In monitoring the progress industry 4.0 progress or readiness, the use of maturity or readiness models have been adopted. A maturity model (MM) is a technique employed to measure several aspects in an organization and to assess the current state of processes for use as starting point for business improvement [7], [6]. It is therefore a tool for measuring, comparing, and describing a path or roadmap [8] and so provides a means of measurement of progress between current assessment and goals, measurements for auditing and benchmarking, understanding for organizations strengths, challenges, and opportunities [9]. Review of the existing Industry 4.0 MMs shows that the different MMs vary in measurement, but majority have built in a level from the lowest to the highest to indicate a set of maturity indicators and several dimensions to express the scope of the models.

\subsection{O\&G Industry Requirements}

Even though some similarities exist between different enterprises for example, the way business is managed in the manufacturing and O\&G Industry, studies and product types show major differences. This section discusses a set of O\&G industry Upstream sector specific requirements that differentiate their business from Manufacturing companies (especially the large and Multi-National Enterprises). The O\&G industry is made up of 3 sectors; Upstream sector involved in exploration and production, the Midstream sector involved in processing, storage and transportation of crude oil, natural gas, natural gas liquids and serving as vital link between the producing areas and the population centers and the Downstream sector basically involved in refining and marketing of hydrocarbon products [10]. 
Taking the perspective of industry sizes, the $O \& G$ industry like the Manufacturing industry, has organizations that could be termed as micro, small, medium, or large (Multi-National Enterprises) [11]. This paper focuses more on the upstream sector of the industry where key business is on exploration and production of crude O\&G for export and sale and for the remainder of this research work, it will be termed the O\&G industry (O\&G industry).

In a review of the O\&G industry and potential for industry 4.0 implementation shows, knowledge is identified as the most critical success factor in every business environment [12]. The study points out that every technology-driven organization needs knowledge management process for more effectiveness and that $O \& G$ industry has taken advantage of this. Adopting digital technologies is very important for organizations into production and this includes the $O \& G$ industry. Digital technology can enhance productivity, efficiency, and safety of operations, cost optimization. The O\&G industry is still at an early stage with deployment of digital technology and deployment is limited to a few areas leading to sub-optimal benefits from the deployment of the technology [13]. Scope, focus, data integration from different vendors with standardization are also seen as key requirements for any organization to succeed in the deployment of some of the industry 4.0 technologies [14], [15], [16], [17], [18]. Managing cyber threats in the O\&G companies would be a step in the right direction help to protect both the physical and virtual facilities in the O\&G sector against cyber-attacks [19] as would availability of work force, finance, technological innovations, work conditions, sound logistics system, robust hardware and software systems, skilled operator, robotic and automation systems do [20], [21], [22].

Data storage, management, value creation, government policies, research \& development plans, clear and flexible IOT architecture, dynamic capabilities are required by the O\&G industry [16], [20], [23]. The O\&G companies are seen as lagging in broad based adoption of big data and as such require big data solutions to economically extract value from the very large volumes date gathered from daily operations. Change management, good planning, collaboration with other industries on technology, education and research, government policy and guidance, funding (financial capability), ethics, privacy, participation in research and model validation, practical knowledge sharing; personnel development, awareness on the technologies, good quality of the data and analysis, interoperability, adaptability, maintenance and obsolescence, mindset of employees are some other very important requirements [24], [18].

Table 1 shows thirteen requirements (Alliances, Collaboration, Competency/Knowledge management, Finance, Government guidance, Logistics system, strategy, organizational culture, people, security systems, standards, Technology/Technical resources, and Environmental considerations) drafted from the reviewed literatures which considered the various viewpoints that are relevant to O\&G industries in line with Industry 4.0.

Table 1. Features of the O\&G industry in line with Industry 4.0

\begin{tabular}{ll}
\hline O\&G Requirements & Comments \\
\hline Alliances & Require alliances with Academia - AL \\
\hline Collaboration & Require collaboration with other industries - CO \\
\hline Competency/Knowledge & Require competency/Knowledge management - \\
management & $\mathrm{CK}$ \\
\hline
\end{tabular}




\begin{tabular}{ll}
\hline Finance & Require funding - FI \\
\hline Government guidance & $\begin{array}{l}\text { Require government guidance and good policies to } \\
\text { promote implementation - GG }\end{array}$ \\
\hline Logistics system & Require Logistics system - LO \\
\hline Strategy & Require strategy for proper implementation ST \\
\hline Organizational culture & Require organizational culture - OC \\
\hline People & Require people - PE \\
\hline Security systems & Require Security systems - SS \\
\hline Standards & Require Industry standards/ standardization - IS \\
\hline Technology/Technical resources & Require Technology/Technical resources - TT \\
\hline Environmental considerations & Require Environmental considerations - EC \\
\hline
\end{tabular}

\section{Research Methodology}

This paper addresses the research questions with the help of a systemic literature review presenting first requirements of $\mathrm{O} \& \mathrm{G}$ industries towards adopting and deploying the technologies. The findings of this literature review indicate that current Industry 4.0 maturity or readiness models and architectures are more skewed towards manufacturing industries. Systematic literature review (SLR) is chosen for reviewing the literature on the $\mathrm{MM}$ and assessment in I.40, as it is a means of evaluating and interpreting all available research information in such a way that it allows reasonable clear conclusions of a particular phenomenon to be reached. The goal is to identify and develop an Industry 4.0 MM that is suitable for the O\&G upstream industry by taking a systematic review of existing MMs available. The scope is limited to literatures on MMs published between 2015 and 2021 (inclusive).

The steps of the systematic methodology adopted are from Preferred Reporting Items for Systematic Reviews and Meta-Analyses: The PRISMA Statement [25] in Figure 1. A combination of keywords and wildcards were used to search for relevant articles in the major bibliographical database such as Google Scholar, Scopus, IEEEX, ScienceDirect and the University Library Catalogue. Tables 2 \& 3 show details of the search keywords, timeline, language and the inclusion and exclusion criteria used to narrow down to a targeted list of articles. The first elimination round was based on sorting the final round was reading the full articles and keeping only the literature based on the research objectives of the systematic review.

Table 2. Search boundaries and keywords

\begin{tabular}{cl}
\hline Search Boundaries & $\begin{array}{l}\text { Google Scholar, Scopus, Science direct, IEEEX, Library Database, Research } \\
\text { Gate, }\end{array}$ \\
\hline Keywords Search & $\begin{array}{l}\text { Industry 4.0 Readiness Model, Industry 4.0 Readiness Framework, Industry 4.0 } \\
\text { Maturity Model in Manufacturing or O\&G Industries }\end{array}$ \\
\hline
\end{tabular}

\section{Results/Findings}

Following the methodology adopted for this paper, 19 MMs were identified, assessed, and analyzed to address the defined research questions (see Table 4). There are 3 research question in this paper, and they are:

- RQ 1: Are the current Industry 4.0 Manufacturing MMs suitable for the specific requirements of $O \& G$ upstream sector?

- RQ2: What are the research gaps that prevents the Industry 4.0 MM from providing full evaluation and support to the O\&G upstream sector? 
- RQ3: How can the current Manufacturing MMs be adapted to support O\&G upstream sector in their evolutionary path towards Industry 4.0 ?

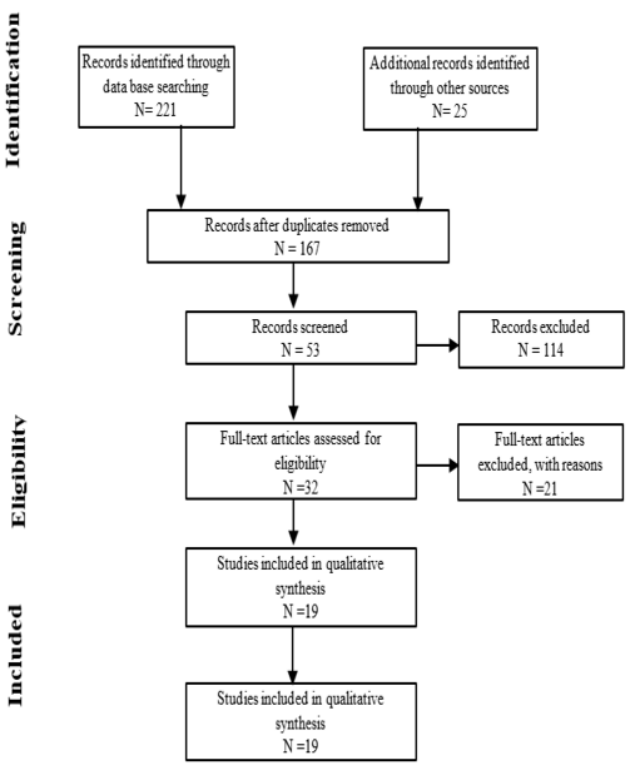

Table 3. Inclusion and exclusion criteria

\begin{tabular}{|c|c|c|}
\hline & Inclusion & Exclusion \\
\hline $\begin{array}{l}\text { Literature } \\
\text { type }\end{array}$ & $\begin{array}{l}\text { Indexed journals, } \\
\text { book chapters, } \\
\text { conference } \\
\text { proceeding, } \\
\text { industry reports }\end{array}$ & $\begin{array}{l}\text { Non-indexed } \\
\text { journals, } \\
\text { magazine articles }\end{array}$ \\
\hline Language & English & Non-English \\
\hline Timeline & $\begin{array}{l}\text { Between years } \\
2014 \text { and } 2021 \\
\text { (inclusive) }\end{array}$ & Before year 2014 \\
\hline Access & $\begin{array}{l}\text { Paper available in } \\
\text { full text }\end{array}$ & $\begin{array}{l}\text { Access to the } \\
\text { document is } \\
\text { restricted }\end{array}$ \\
\hline $\begin{array}{l}\text { Research } \\
\text { title }\end{array}$ & $\begin{array}{l}\text { A paper does not } \\
\text { provide the } \\
\text { research on } \\
\text { Industry } 4.0\end{array}$ & $\begin{array}{l}\text { A paper does not } \\
\text { provide the } \\
\text { research on } \\
\text { Industry } 4.0\end{array}$ \\
\hline $\begin{array}{l}\text { Key } \\
\text { Research } \\
\text { information }\end{array}$ & $\begin{array}{l}\text { Contains and } \\
\text { discusses Industry } \\
4.0 \mathrm{MM} \text { in } \\
\text { manufacturing or } \\
\text { O\&G industries }\end{array}$ & $\begin{array}{l}\text { Does not contain } \\
\text { or discuss } \\
\text { Industry } 4.0 \mathrm{MM} \\
\text { in manufacturing } \\
\text { or O\&G industries }\end{array}$ \\
\hline Article type & $\begin{array}{l}\text { New MM proposed } \\
\text { related to industry } \\
4.0 \text { with } \\
\text { information on the } \\
\text { newly proposed }\end{array}$ & $\begin{array}{l}\text { A paper is the } \\
\text { review article of } \\
\text { the existing MMs } \\
\text { and does not } \\
\text { propose any MM }\end{array}$ \\
\hline
\end{tabular}

Figure 1. PRISMA flowchart adapted from [26]

\subsection{Verifying Current Maturity Model Fit with Oil \& Gas Industry Specific Requirements}

One of the discoveries from this study is that adopting Industry 4.0 in the O\&G industry brings an opportunity to achieve improved efficiency and cost savings in O\&G plant operations. A key finding is that the current Industry 4.0 MMs are not fully suitable for the industry as the key requirements identified are not met.

Information on this finding have been dealt with in section 1.1 where a review was done on the requirements of the $O \& G$ industry. Having categorized the identified requirements, an overview of how the nineteen models meets these identified O\&G requirements are presented in Table 4 . The " $\sqrt{ }$ " signifies that that the provisions for the specific requirements of the $O \& G$ industry are met and where the boxes are blank, it implies that the model does not meet those requirements. From the overview of the analysis, no maturity model meets all the requirements of the O\&G industry.

\subsection{Gaps That Prevent Current Manufacturing MMs from Providing Full Evaluation and Support to the O\&G Upstream Sector}

Table 4 presents the list of the nineteen models with information on the number of dimensions, maturity levels and industry scope. First on the findings is that fact that all the models do not capture or consider the O\&G industry scope. The manufacturing industry is the application industry for a high percentage of the industry 4.0 MMs. Deployment of the technologies have already begun in the O\&G however, there are no 
readiness assessments or MMs specifically designed to measure the progress in the $\mathrm{O}$ $\& \mathrm{G}$ industry.

Six of these articles have acknowledged clearly the use of professional's workshop conceptualization, surveys, feedback, from relevant industries or pilot studies for finalizing and validating the maturity items however there are gaps around the number persons, industries and subjectivity during the validation and limitation to specific industries where they were validated and of which none mentioned model validation with the O\&G industry. Two of them are yet to be validated with the industry and the others have no clear information about their validation. Model validation is very key for every model and has to do with comparing model outputs to independent real-world observations so to judge the quantitative and qualitative correspondence with reality [27]. Model validation helps to track known model limitations and identify any new potential shortcomings. So, they are a means of adding value to the industry.

The individual researchers seem to have varying views and understanding of dimensions and maturity levels. The disconnects between the MMs can be considered as another research gap that needs to be considered. The O\&G industry would require a fit for purpose maturity model employing solutions to the identified gaps identified with dimensions that would capture the scope of all requirements identified in this study.

Table 4. List of Industry 4.0 Maturity Models

\begin{tabular}{|c|c|c|c|c|c|c|c|c|c|c|c|c|}
\hline Models & ALCO & CK & FI & GG & LO & ST & $\mathrm{OC}$ & PE & SS II & IS 1 & TT & EC \\
\hline Development of an Assessment Model for Industry 4.0: Industry 4.0-MM & & & & & & & & $\sqrt{ }$ & & & $\sqrt{ }$ & \\
\hline $\begin{array}{l}\text { Model to evaluate the Industry } 4.0 \text { readiness degree in Industrial } \\
\text { Companies }\end{array}$ & & & & & & & & & $\sqrt{ }$ & & $\sqrt{ }$ & \\
\hline $\begin{array}{l}\text { Developing an Industry } 4.0 \text { Readiness Model for Indian Engineering } \\
\text { Industries }\end{array}$ & & & & & & $\sqrt{ }$ & $\sqrt{ }$ & $\sqrt{ }$ & & & $\sqrt{ }$ & \\
\hline An Industry 4.0 maturity model for machine tool companies & & & & & & $\sqrt{ }$ & $\sqrt{ }$ & $\sqrt{ }$ & & & $\sqrt{ }$ & \\
\hline $\begin{array}{l}\text { SIMMI 4.0 - A Maturity Model for Classifying the Enterprise-wide IT } \\
\text { and Software Landscape Focusing on Industry } 4.0\end{array}$ & & & & & & & $\sqrt{ }$ & & & & $\sqrt{ }$ & \\
\hline Strategic guidance towards Industry $4.0-$ a three-stage process model & & & & & & & $\sqrt{ }$ & & & & $\sqrt{ }$ & \\
\hline Maturity and Readiness Model for Industry 4.0 Strategy & & & & & & $\sqrt{ }$ & $\sqrt{ }$ & & & & $\sqrt{ }$ & \\
\hline $\begin{array}{l}\text { Concept of Industry 4.0-Related Manufacturing Technology Maturity } \\
\text { Model (ManuTech Maturity Model - MTMM) }\end{array}$ & & $\sqrt{ }$ & & & & & $\sqrt{ }$ & $\sqrt{ }$ & $\sqrt{ }$ & & $\sqrt{ }$ & \\
\hline Digital Maturity: Definition and Model & & & & & & $\sqrt{ }$ & $\sqrt{ }$ & $\sqrt{ }$ & & & $\sqrt{ }$ & \\
\hline The Digital Maturity Model 4.0 & & & & & & & $\sqrt{ }$ & & & & $\sqrt{ }$ & \\
\hline $\begin{array}{l}\text { A maturity model for assessing Industry } 4.0 \text { readiness and maturity of } \\
\text { manufacturing enterprises }\end{array}$ & & & & $\sqrt{ }$ & & $\sqrt{ }$ & $\sqrt{ }$ & $\sqrt{ }$ & $\sqrt{ }$ & & $\sqrt{ }$ & \\
\hline $\begin{array}{l}\text { For a better understanding of Industry } 4.0-\text { An Industry } 4.0 \text { maturity } \\
\text { model }\end{array}$ & & & & $\sqrt{ }$ & & $\sqrt{ }$ & $\sqrt{ }$ & $\sqrt{ }$ & $\sqrt{ }$ & & $\sqrt{ }$ & \\
\hline $\begin{array}{l}\text { Road mapping towards industrial digitalization based on an industry } 4.0 \\
\text { maturity model for manufacturing enterprises }\end{array}$ & & & & $\sqrt{ }$ & & $\sqrt{ }$ & $\sqrt{ }$ & $\sqrt{ }$ & & $\sqrt{ }$ & $\sqrt{ }$ & \\
\hline An Industry 4.0 maturity model proposal & & & & & & $\sqrt{ }$ & $\sqrt{ }$ & $\sqrt{ }$ & & & $\sqrt{ }$ & \\
\hline $\begin{array}{l}\text { Development of a Digitalization Maturity Model for the manufacturing } \\
\text { sector }\end{array}$ & & & & & & $\sqrt{ }$ & $\sqrt{ }$ & $\sqrt{ }$ & & & $\sqrt{ }$ & \\
\hline $\begin{array}{l}\text { Development of maturity model for assessing the implementation of } \\
\text { Industry 4.0: learning from theory and practice }\end{array}$ & & $\sqrt{ }$ & $\sqrt{ }$ & & & $\sqrt{ }$ & & $\sqrt{ }$ & $\sqrt{ }$ & & $\sqrt{ }$ & \\
\hline Three Stage Maturity Model in SME's towards Industry 4.0 & & & $\sqrt{ }$ & & & & & $\sqrt{ }$ & & & $\sqrt{ }$ & \\
\hline $\begin{array}{l}\text { A maturity assessment approach for conceiving context-specific roadmaps } \\
\text { in the Industry } 4.0 \text { era }\end{array}$ & & & $\sqrt{ }$ & $\sqrt{ }$ & $\sqrt{ }$ & & & & & & $\sqrt{ }$ & \\
\hline Concept for an evolutionary maturity based Industrie 4.0 migration model & & & & & & & $\sqrt{ }$ & $\sqrt{ }$ & & & $\sqrt{ }$ & \\
\hline
\end{tabular}

\subsection{How the Current Manufacturing Maturity Models Can be Adapted to Support the Oil \& Gas Upstream Sector}

Some of the benefits of deploying Industry 4.0 maturity model are standardization in development, higher quality, global competition among strong businesses, more 
flexibility, continuous benchmarking and improvement, creation of appealing jobs at the intersection of mechanical engineering, automation, and IT, new services, and business models. The O\&G industries, having its own specific needs specific different from all other industries would certainly need to have Industry 4.0 Maturity model tailored to lead the industry from readiness into full implementation of industry 4.0 technologies. Knowledge management and competence development in the emerging technologies is crucial to helping the O\&G industry development in Industry 4.0. Progressing on the ongoing journey of digitalization, support from the academia and consultants in the concept of Industry 4.0 are some other means of bringing about the desired progress in industry 4.0.

Summarily, making the MM for the O\&G industry to satisfy the requirements of the $\mathrm{O} \& \mathrm{G}$ industries and fully tailoring the $\mathrm{MM}$ to the increasingly and more dynamic nature of the O\&G processes would be a good way to making the manufacturing MMs adaptable for support to the $\mathrm{O} \& \mathrm{G}$ sector in the journey to maturity adapting the Industry 4.0 technologies.

\section{Conclusions, limitations, and future work}

The specific requirements of the O\&G upstream sector formed kick off point of this study and this was through a review of literatures. Through a systematic review of industry 4.0 MMs, three guiding research questions were answered, and the result of the review shows that most of the articles mainly considered the manufacturing industries and as such the requirements of the O\&G industries are not met by the selected models. The major findings from this study need to be addressed to support to the O\&G sector in the onward towards Industry 4.0 implementation.

The major limitation of this paper is that it based on a literature review, no primary research data collected and most of the available literature on MMs are focused on the manufacturing industry. Little or no consideration is given to geographical location or environmental conditions in these models. Though some O\&G industries (especially the multinationals) have kicked-off the 4.0 journey and are ahead of others, but a generalization was done, study did not consider the sizes and types of O\&G industries. There are claims that some of the MMs are suitable for many industries however, as there is no distinct and clear information of validation in the $O \& G$, such MMs were not considered as being suitable for the O\&G. Based on the need identified in this paper, the aim of the proposed research is to develop an Industry 4.0 implementation readiness model to show levels of adoption of Industry 4.0 technologies in the O\&G industry.

\section{References}

[1] H. Lu, L. Guo, M. Azimi, and K. Huang, "Oil and Gas 4.0 era: A systematic review and outlook," Computers in Industry, vol. 111. Elsevier B.V., pp. 68-90, Oct. 01, 2019.

[2] M. Mohammadpoor and F. Torabi, "Big Data analytics in oil and gas industry: An emerging trend," Petroleum, vol. 6, no. 4. KeAi Communications Co., pp. 321-328, Dec. 01, 2020.

[3] H. Lu, K. Huang, M. Azimi, and L. Guo, "Blockchain technology in the oil and gas industry: A review of applications, opportunities, challenges, and risks," IEEE Access, vol. 7, pp. 41426-41444, 2019.

[4] S. Chen, H. Xu, D. Liu, B. Hu, and H. Wang, "A vision of IoT: Applications, challenges, and opportunities with China Perspective," IEEE Internet of Things Journal, vol. 1, no. 4. Institute of Electrical and Electronics Engineers Inc., pp. 349-359, Aug. 01, 2014.

[5] E. Gökalp, U. Şener, and P. E. Eren, "Development of an assessment model for industry 4.0: Industry 4.0MM," in Communications in Computer and Information Science, 2017, vol. 770, pp. 128-142. 
[6] W. C. Lucato, A. P. T. Pacchini, F. Facchini, and G. Mummolo, "Model to evaluate the Industry 4.0 readiness degree in Industrial Companies," IFAC-PapersOnLine, vol. 52, no. 13, pp. 1808-1813, 2019 ,

[7] L. S. Angreani, A. Vijaya, and H. Wicaksono, "Systematic Literature Review of Industry 4.0 Maturity Model for Manufacturing and Logistics Sectors," Procedia Manufacturing, vol. 52, pp. 337-343, 2020.

[8] L. Stefan, W. Thom, L. Dominik, K. Dieter, K. Bernd, and D. et al. ; P. S. V. XPRES, "Concept for an evolutionary maturity based Industrie 4.0 migration model," in 51st CIRP Conference on Manufacturing Systems, CIRP CMS 2018, 2018, vol. 72, pp. 404-409.

[9] D. Proença and J. Borbinha, "Maturity Models for Information Systems - A State of the Art," in Procedia Computer Science, 2016, vol. 100, pp. 1042-1049.

[10] ICSI, “OIL AND GAS INDUSTRY,” 2018. [Online]. Available: www.icsi.edu,

[11] European Union, "User guide to the SME definition," 2020. Accessed: Mar. 20, 2021. [Online]. Available: https:/ec.europa.eu/docsroom/documents/42921/attachments/1/translations/en/renditions/native

[12] C. Ramanigopal Professor, "KNOWLEDGE MANAGEMENT FOR THE OIL AND GAS INDUSTRY: OPPORTUNITIES AND CHALLENGES," Asian Journal of Business and Economics, vol. 2, no. 2, 2012.

[13] T. R. Wanasinghe, R. G. Gosine, L. A. James, G. K. I. Mann, O. de Silva, and P. J. Warrian, "The Internet of Things in the Oil and Gas Industry: A Systematic Review," IEEE Internet of Things Journal, vol. 7, no. 9, pp. 8654-8673, Sep. 2020.

[14] D. B. Cameron, A. Waaler, and T. M. Komulainen, "Oil and Gas digital twins after twenty years. How can they be made sustainable, maintainable and useful?," in Proceedings of The 59th Conference on Simulation and Modelling (SIMS 59), 26-28 September 2018, Oslo Metropolitan University, Norway, Nov. 2018, vol. 153, pp. 9-16.

[15] P. AARON and W. LANE, "Industry 4.0 and the digital twin Manufacturing meets its match A Deloitte series on Industry 4.0, digital manufacturing enterprises, and digital supply networks," 2017.

[16] M. S. Hajirahimova, “Opportunities and challenges big data in oil and gas industry," 2015. [Online]. Available: https://www.researchgate.net/publication/305993382

[17] T. R. Wanasinghe, R. G. Gosine, O. de Silva, G. K. I. Mann, L. A. James, and P. Warrian, "Unmanned Aerial Systems for the Oil and Gas Industry: Overview, Applications, and Challenges," IEEE Access, vol. 8, pp. 166980-166997, Aug. 2020.

[18] A. Rasheed, O. San, and T. Kvamsdal, "Digital Twin: Values, Challenges and Enablers," Oct. 2019, [Online]. Available: http://arxiv.org/abs/1910.01719

[19] R. Das and T. Morris, "Modeling a midstream oil terminal for cyber security risk evaluation," in IFIP Advances in Information and Communication Technology, 2018, vol. 542, pp. 149-175.

[20] H. Chen, S. Stavinoha, M. Walker, B. Zhang, and T. Fuhlbrigge, "Opportunities and Challenges of Robotics and Automation in Offshore Oil \&amp; Gas Industry," Intelligent Control and Automation, vol. 05, no. 03, pp. 136-145, 2014, doi: 10.4236/ica.2014.53016.

[21] A. Shukla and H. Karki, "Application of robotics in onshore oil and gas industry-A review Part i," Robotics and Autonomous Systems, vol. 75, pp. 490-507, Jan. 2016.

[22] A. Shukla and H. Karki, "Application of robotics in offshore oil and gas industry-A review Part II," Robotics and Autonomous Systems, vol. 75, pp. 508-524, Jan. 2016.

[23] A. Shuen, P. F. Feiler, and D. J. Teece, "Dynamic capabilities in the upstream oil and gas sector: Managing next generation competition," Energy Strategy Reviews, vol. 3, no. C, pp. 5-13, 2014.

[24] Y. Lu, "Industry 4.0: A survey on technologies, applications and open research issues," Journal of Industrial Information Integration, vol. 6, pp. 1-10, Jun. 2017.

[25] D. Moher et al., "Preferred reporting items for systematic reviews and meta-analyses: The PRISMA statement," PLoS Medicine, vol. 6, no. 7. Jul. 2009.

[26] C. Leyh, K. Bley, T. Schaffer, and S. Forstenhausler, "SIMMI 4.0-a maturity model for classifying the enterprise-wide it and software landscape focusing on Industry 4.0," in Proceedings of the 2016 Federated Conference on Computer Science and Information Systems, FedCSIS 2016, Nov. 2016, pp. 1297-1302.

[27] P. Dijkstra and S. C. van de Geijn, "Model Validation Response of Growth and CO2 Uptake of Spring Wheat and Faba Bean to CO2 Concentration under Semi-field Conditions: Comparing Results of Field Experiments and Simulations," 1996. 